\title{
IMPACT OF RASTER COMPRESSION ON THE PERFORMANCE OF A MAP APPLICATION
}

\author{
Karol Król, Agnieszka Bitner
}

\begin{abstract}
Summary
Raster publications provide one alternative to database-based technologies, and despite their limitations, they may be used in the presentation of data having spatial reference. Image browser performance can have a particular impact on the comfort of its use. The aim of the present work is to analyse the relationships between the degree of raster compression and the performance of the map application. The research was carried out in an informal manner, under conditions of typical use, in the form of ad-hoc tests. The measurement was performed using three applications that automate tests: (1) Cloudinary Website Speed Test Image Analysis Tool, (2) GTmetrix, and (3) Dareboost. It has been shown that in applications based on raster maps, which are of an illustrative, temporary and at the same time ad-hoc nature (ad-hoc maps), maintaining high quality images at the expense of application performance is not justified.
\end{abstract}

\section{Keywords}

WebP files • raster files $\bullet$ performance $\bullet$ website speed $\bullet$ ad-hoc maps

\section{Introduction}

Maps on the Internet are published using many various techniques and design tools. They are available in the form of a variety of mapping websites, including geoportals [Farkas 2017] or components of other websites [Król and Szomorova 2015]. Also dynamically developing, web geographic information systems (WebGIS) operate in the client-server architecture and consist of a map server, database, and user interface [Kocur-Bera and Dudzińska 2014]. The map server is an independent machine whose task is to generate maps with given parameters, based on data having spatial reference. Its basic functions include: visualization, navigation, and spatial analyses [KocurBera 2011]. Currently, scripting languages operating on the client's end are the most commonly used for creating user interface in WebGIS systems. Among them, AJAX technology is very popular. The latter allows asynchronous communication of the user with the server, so that when the action is performed, only the selected area of the site is re-loaded [Malicka and Żyła 2011]. A certain alternative to database-founded 
technologies is provided by raster publications, which, despite their limitations, may be used in the presentation of data having spatial reference.

Performance is one of the most important attributes that testify to the quality of web applications. About 39\% of Internet users say that the speed of a website is more important than its functionality [Akamai 2017]. Image browser performance can have a special impact on the comfort of its use [Król 2018a]. The dynamics of loading images depends in particular on the size of the file. The map application performance threshold, also understood as the threshold of the comfort of its use, furthermore depends on the device on which it is viewed, on the speed of the server and the Internet connection. The application's architecture should be different for mobile devices than for stationary devices. Therefore, the way in which the image presentation is programmed, and the degree of its compression will be of great importance [Król 2018b].

\section{Purpose and goals of the study}

The digital image can be saved in the computer's memory as a graphic file. The choice of format depends, for instance, on the intended use of the image. In the case of raster graphics it is possible to save the file in one of many formats, among which the most popular are BMP, JPG, GIF, TIF and PNG. Another, less frequently used format is the WebP format.

WebP is a new format for lossy image compression developed by Google in 2010. It is based on the VP8 video codec with a Resource Interchange File Format (RIFF) container [Ginesu et al. 2012]. The idea of WebP is to be a new open standard for compressed graphics on the Internet, as an alternative to such formats as JPG. Compared with the present popular image format, WebP has smaller volume than JPG and PNG in the condition of the same picture quality conditions [Si and Shen 2016]. The aim of the present work is to analyse the relationships between the degree of raster compression and the performance of the map application. A research question was posed: to what extent does the application of raster saved in the WebP format affect the performance of the mapping application? The answer to this question can provide arguments for choosing the most effective way to compress graphic files.

\section{Data compression matters}

Research into a wide range of hypertext systems has shown that users expect a response time of less than one second when switching from one web page to another. Such speed allows them to move freely in the information space. Currently, the minimum goal for response times should therefore be to get pages to users in no more than ten seconds, since that's the limit of people's ability to keep their attention focused while waiting. Web applications should therefore be designed with their performance in mind. In order to minimize the size of websites, the graphics should be limited to a reasonable minimum (of course, adequately to the website's function), just like the number of components of the website, and multimedia effects should only be used if they actually enhance the comprehension of the information content [Nielsen 1997]. 
The performance of web applications depends on several key factors, including server performance (hosting), optimal source code, and Internet connection. The speed of the Internet connection depends on the service configuration. This also applies to server performance. Yet even the fastest server can remain unused if the source code of the application - i.e. the way it is constructed - is not optimal. Application performance can also be affected by the components used to create it, including various scripts and libraries. Furthermore, slow loading of web applications is often caused by the use of large graphic files [Nielsen 2010]. This can be remedied by compressing them. The use of compression can significantly reduce the file size [Brailovskiy and Plotkin 2008].

Compression can be defined as the process of transforming a source dataset into a representation with fewer bits. The inverse process (or reconstruction of the original data set) is called decompression. Compression efficiency is understood as minimizing the size of data compressed in relation to the original set [Boniecki et al. 2009].

Basically, compression methods can be divided into lossless and lossy. In lossless compression, the data string obtained after the transformation is identical to the source set. Lossless compression can therefore be called a reversible, or numerically lossless. Lossless algorithms are used when the image is treated as a document, that is - among others - in the case of medical images that are the basis for the diagnosis, as well as when the image will be subject to further processing [Starosolski 2004]. The result of lossless compression can take the form of PNG files (Portable Network Graphics), which are created for the purpose of publishing on the Internet.

For compressing typical images, lossy algorithms are commonly used. Lossy compression does not allow for the reproduction of source data with accuracy down to one byte. Therefore, it is referred to as numerically lossy, or irreversible compression [Boniecki et al. 2009]. In the case of typical images, the loss of information in the compression-decompression process remains in most cases imperceptible to the human eye, and therefore it can be tolerated. Thus, lossy algorithms are referred to as "visually lossless". An example of lossy compression that causes changes in the recorded image is compression to a JPG (Joint Photographic experts Group) file. However, the (slight) deterioration of picture quality is not always significant. Each picture contains so-called noise. An image change not exceeding the noise level is not relevant to the image quality. If you do not analyse the noise itself, the use of lossy compression that changes the image at a level that does not exceed the noise provides the same image quality (for the recipient) as lossless compression [Borawski 2011]. Image compression may become noticeable if the conditions of observation are changed or the image is further processed [Boniecki et al. 2009].

\section{Material and methods}

The tests were administered to a prototype application created with the aid of HTML, CSS, graphic files, and the Mapbox component: Zoomable jQuery Map Plugin (MIT License) [Mohler 2019]. The Mapbox component: Zoomable jQuery Map Plugin was chosen due to the low hardware requirements and the lack of restrictions on the size of the presented images. The essential part of the application is the raster files in any 
format, superimposed on each other in the application's dialogue window. The Mapbox plugin makes it possible to view raster graphics, including dragging and dropping the map area. The "zoom" effect here is realized by eliciting individual raster versions one after the other (Fig. 1).

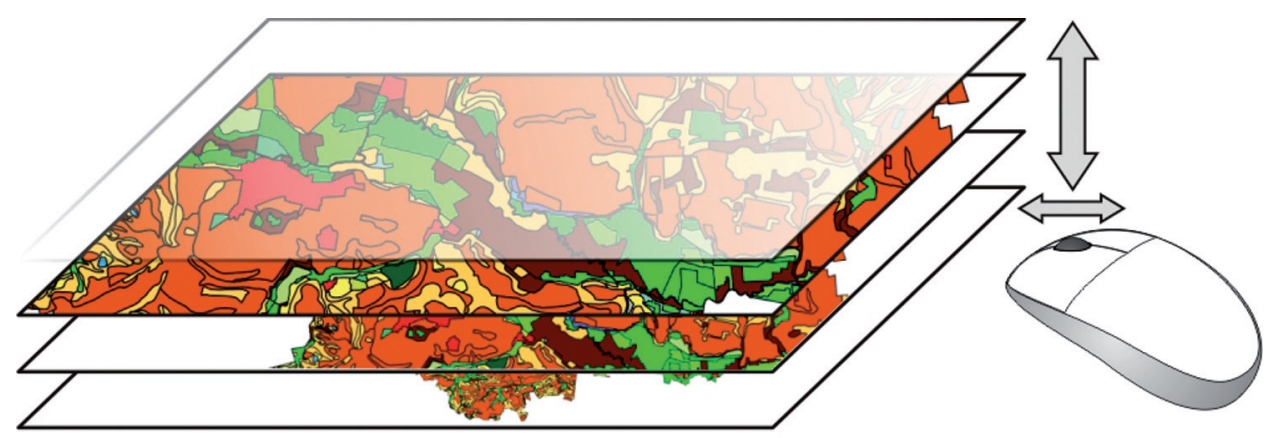

Source: developed by the Author

Fig. 1. Schematic drawing of rasters' superimposition in the work window of an application developed using Mapbox

The research was conducted in an informal manner, under conditions of typical use, in the form of ad-hoc tests (these tests are also referred to as: "Expert Testing" or "Monkey Testing"). Ad-hoc (exploration) tests are the least formal method of testing, of Internet applications among other things. This type of tests can be spontaneous, it facilitates becoming familiar with the nature of the tested application, and it is carried out without creating a formal test plan. Ad-hoc tests are helpful when planning other types of tests, including formal tests, i.e. such that are carried out in laboratory conditions [Król 2016]. The measurement was performed using three applications that automate tests: (1) Cloudinary Website Speed Test Image Analysis Tool, (2) GTmetrix, and (3) Dareboost.

Cloudinary Website Speed Test Image Analysis Tool analyzes a website's images and provides a ranking for a variety of image aspects and categories. Using a grade range of A-F, it rates the image format, fit, compression rate, color space and color depth. Along with the ranking, the Website Speed Test tool provides measurable information about how to go beyond simple compression to optimize web performance. The GTmetrix app measures, among other things, website performance and its loading time in the browser window. The results of performance measurement are presented using the PageSpeed Score and YSlow indicators. The values of indicators are given in the range from 0 to 100 percentage points. The Dareboost app provides, among other things, the results of the Mobile Speed Index measurement; whereas the higher the efficiency of the application, the lower the index value. It is recommended that the index value should not exceed 1000 units. 
Spatial data can be represented in two formats, raster or vector. It is inevitable that conversion of the data between these two formats be essential to the best use of the data. Most geographic information systems (GIS) now provide software for such a conversion [Congalton 1997]. Three versions of the web application were tested for performance. The application in the first and the second version presented images (raster files) in their original version, generated in the form of JPG and PNG files from the GIS vector layer. Then, these rasters were compressed using the Cloudinary tool and saved in the WebP format. Cloudinary is the media management platform for web and mobile developers. An end-to-end solution for all your image and video needs. In addition, the F-Score performance index [King 2018a] was calculated.

Empirical values of diagnostic features are expressed in numbers. This prevents the values of the individual features from being freely added up. For this reason, the methods of combining traits and their reduction are beneficial in the research process. Thanks to normalization, the values of variables expressed in different units become comparable, which facilitates adding up qualitatively different features.

The normalization was performed with the aid of zero unitarisation, which uses the maximum and minimum values. Previously, however, diagnostic variables were divided into stimulants and deterrents (Table 1).

Table 1. Subdivision of diagnostic variables according to type

\begin{tabular}{|c|l|c|c|}
\hline Testing application & Diagnostic variable & Unit of measurement & Type of variable \\
\hline \multirow{3}{*}{ GTmetrix } & PageSpeed Score & $\%$ & $\mathrm{~S}$ \\
\cline { 2 - 4 } & YSlow & $\%$ & $\mathrm{~S}$ \\
\cline { 2 - 4 } & Fully Loaded Time & second $[\mathrm{s}]$ & $\mathrm{D}$ \\
\hline \multirow{3}{*}{ Dareboost } & Performance grade & $\%$ & $\mathrm{~S}$ \\
\cline { 2 - 4 } & Speed Index & point & $\mathrm{D}$ \\
\hline
\end{tabular}

S - stimulant, D - deterrent

Source: Author's own study

Stimulants are variables whose high values are desirable from the point of view of the studied phenomenon. In the case of deterrents, the lowest possible values of variables are expected [Prus et al. 2018]. In the zero unitarisation method there is a fixed reference point, which is the distribution of the normalized variable $R\left(X_{j}\right)=\max _{i}\left\{x_{i j}\right\}$ $-\min _{i}\left\{x_{i j}\right\}$. The normalization of the stimulants is carried out using the formula (1):

$$
z_{i j}=\frac{x_{i j}-\min _{i}\left\{x_{i j}\right\}}{\max _{i}\left\{x_{i j}\right\}-\min _{i}\left\{x_{i j}\right\}} \quad i=1,2, . ., n ; j=1,2, \ldots, m
$$

where $z_{i j} \in[0,1]$. Further: $z_{i j}=0 \Leftrightarrow x_{i j}=\min _{i}\left\{x_{i j}\right\}$ and

$$
z_{i j}=1 \Leftrightarrow x_{i j}=\max _{i}\left\{x_{i j}\right\} \text {. }
$$


Normalization of deterrents is carried out using the formula (2):

$$
z_{i j}=\frac{\max _{i}\left\{x_{i j}\right\}-x_{i j}}{\max _{i}\left\{x_{i j}\right\}-\min _{i}\left\{x_{i j}\right\}} \quad i=1,2, . ., n ; j=1,2, \ldots, m
$$

where $z_{i j} \in[0,1]$. Further: $z_{i j}=0 \Leftrightarrow x_{i j}=\max _{i}\left\{x_{i j}\right\}$ and

$$
z_{i j}=1 \Leftrightarrow x_{i j}=\min _{i}\left\{x_{i j}\right\} \text {. }
$$

In order to obtain one evaluation from the many standardized features characterizing an object, all variables normalized for each object should be added up. In this way, each object is described by one synthetic aggregate mark.

The dimensionless quantities obtained as a result of standardization remain in the same relation to each other as the corresponding dimensioned quantities assigned before the normalization. The F-Score index (the aggregate variable) is the result of adding up the normalized values of individual diagnostic variables.

\section{Results and implications}

The result of the implementation of the Mapbox: Zoomable jQuery Map Plugin [Mohler 2019] was an online application that allows viewing the raster map (Fig. 2). The soil map of the Proszowice municipality, created using the QGIS software, served as the map base. Proszowice municipality is located in the northern part of the Małopolska region (Poland) in the Płaskowyż Proszowicki (Proszowice Plateau) [Król and Prus 2017].

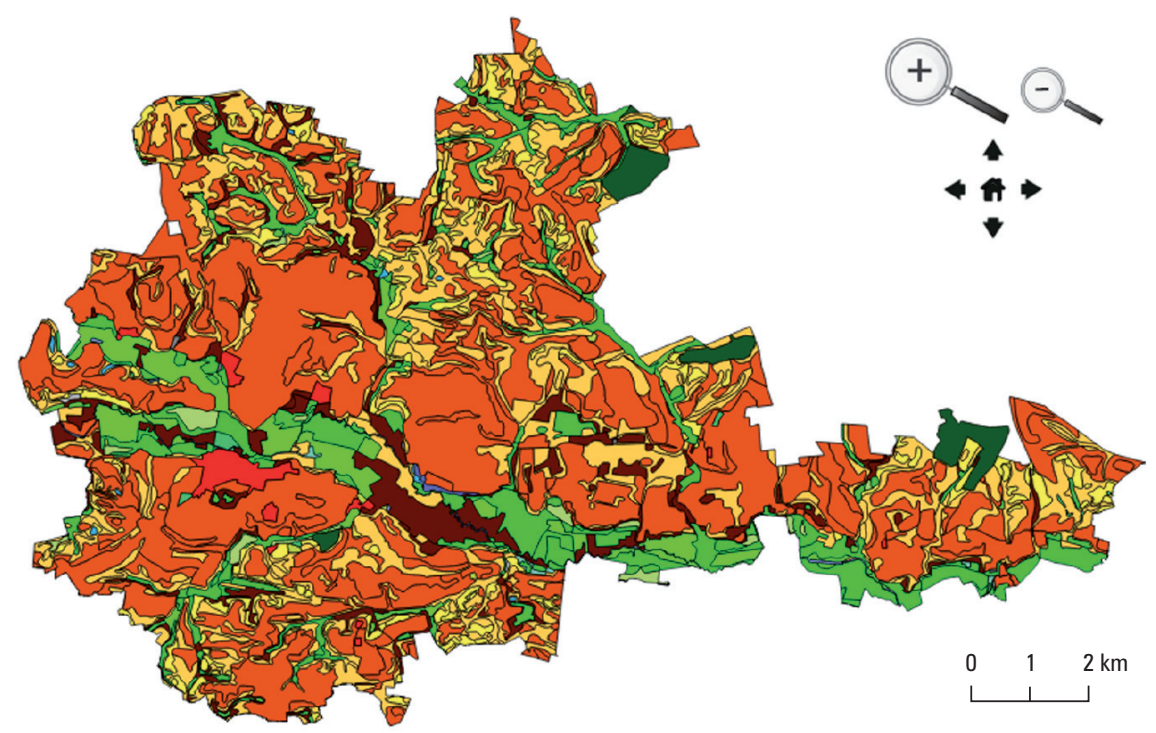

Source: Author's own study

Fig. 2. Window of an online app created using the Mapbox component (screen shot) 
Raster files were prepared in three packages of five images each, with each image in different resolution (Table 2). Such image preparation was supposed to increase the usability of the application, and guarantee a relatively high burden on the client (the client being a device together with the appropriate client software, supporting the application created in the client-server architecture). The first package contained JPG files with a total size of approx. $7 \mathrm{MB}$, while the second contained PNG files with a total size of approx. $11 \mathrm{MB}$. The third package contained files saved in the WebP format with a total size of around $5 \mathrm{MB}$.

Table 2. Attributes of rasters making up particular versions of the app

\begin{tabular}{|c|c|c|c|c|}
\hline Raster file & Size $[\mathrm{px}]$ & JPG file size $[\mathrm{KB}]$ & PNG file size $[\mathrm{KB}]$ & WebP file size [KB] \\
\hline 1 & $841 \times 595$ & 119 & 328 & 97 \\
\hline 2 & $1753 \times 1240$ & 423 & 887 & 237 \\
\hline 3 & $3507 \times 2480$ & 1197 & 2046 & 872 \\
\hline 4 & $5261 \times 3720$ & 2168 & 3242 & 1507 \\
\hline 5 & $7015 \times 4960$ & 3309 & 4453 & 2135 \\
\hline Total & $\mathrm{n} / \mathrm{a}$ & 7216 & 10956 & 4848 \\
\hline
\end{tabular}

Source: Author's own study

Tests made with the aid of the Website Speed Test application confirmed that the greatest capacity for image compression was afforded in the case of PNG files. It was possible to convert them to the WebP format and reduce their volume by up to $60 \%$ (Table 3). Compression of raster prepared in JPG and WebP, according to Website Speed Test, would not produce equally big benefits. This is due to the fact that these are extensions of files already compressed. It would therefore enable "compression of files already compressed", so to speak. Notwithstanding the relatively big capacity of reducing the volume of images, the performance of all applications, regardless of the type of raster used, was rated as good. It can be concluded that this is due to the nature of the app itself, which was created in the form of a small component.

The values of PageSpeed Score and YSlow are calculated in a different way. When analysing the values of the YSlow indicator, it can be concluded that during its calculation, the size of graphic files is not taken into account - as the values of this indicator were the same, regardless of the size of the image package (Table 4). Particular attention is paid to the size of the PageSpeed Score calculated in the case of an application that uses PNG files. Analysis of the measurements leads to the conclusion that PageSpeed Score depends, among other things, on the size of graphic files that make up the application. 
Table 3. Results of performance tests carried out with the aid of Website Speed Test

\begin{tabular}{|l|c|c|c|}
\hline \multicolumn{1}{|c|}{ Index } & $\begin{array}{c}\text { Version I } \\
\text { (JPG) }\end{array}$ & $\begin{array}{c}\text { Version II } \\
\text { (PNG) }\end{array}$ & $\begin{array}{c}\text { Version III } \\
\text { (WebP) }\end{array}$ \\
\hline Page Image Score & \multicolumn{3}{|c|}{ B (Good) } \\
\hline Total Images Analyzed & \multicolumn{2}{|c|}{10} \\
\hline Image Weight Comparison, Current Images (MB) & 1.8 & 3.3 & 1.2 \\
\hline $\begin{array}{l}\text { Image Weight Comparison, Potential after Smart } \\
\text { Compression (MB) }\end{array}$ & 1.4 & 1.2 & 1.1 \\
\hline Potential Compressed Weight [\%] & $76.9(23.1)$ & $63.1(36.9)$ & $94.2(5.8)$ \\
\hline
\end{tabular}

Source: Author's own study

Table 4. Measurement results for selected performance indices (desktop mode)

\begin{tabular}{|l|c|c|c|c|c|c|}
\hline \multicolumn{1}{|c|}{ Analytic tool } & $\begin{array}{c}\text { GTmetrix } \\
\text { PageSpeed } \\
\text { Score [\%] }\end{array}$ & $\begin{array}{c}\text { GTmetrix } \\
\text { YSlow } \\
{[\%]}\end{array}$ & $\begin{array}{c}\text { GTmetrix } \\
\text { Fully Loaded } \\
\text { Time [s] }\end{array}$ & $\begin{array}{c}\text { Dareboost } \\
\text { Performance } \\
\text { grade [\%] }\end{array}$ & $\begin{array}{c}\text { Dareboost } \\
\text { Speed Index } \\
\text { [points] }\end{array}$ & F-Score \\
\cline { 1 - 5 } Type of the variable & $S\left(X_{1}\right)$ & $S\left(X_{2}\right)$ & $D\left(X_{3}\right)$ & $S\left(X_{4}\right)$ & $D\left(X_{5}\right)$ & \\
\cline { 1 - 5 } Version I (JPG) & 64 & 77 & 3.5 & 58 & 1042 & 2.98 \\
\hline Version II (PNG) & 24 & 77 & 3.7 & 59 & 1788 & 1.33 \\
\hline Version III (WebP) & 86 & 77 & 3.1 & 61 & 1159 & 4.84 \\
\hline
\end{tabular}

Source: Author's own study

The low value of the YSlow index for the application made in the second version (PNG files) is accompanied by a low value of the Speed Index (measurement in desktop mode, Paris, France). It is also worth noting that, in each case, the Speed Index value exceeded the recommended 1000 units. This leads to the conclusion that in the case of the application made in the second version (PNG files) the low efficiency was caused by the use of two rasters were, of which the size of one reached almost 4.5MB. To compare, its counterpart with the WebP extension was more than twice as small.

The highest value of the F-Score index was obtained for the application in which WebP files were used, whereas the lowest (worst) value was obtained by the application created based on PNG files. The measurements of GTmetrix PageSpeed Score and Dareboost Speed Index determined this. At this point, however, it is worth noting that the study concerned the application's performance on stationary devices (desktop mode). Tests carried out on mobile devices (measurement in mobile mode: Galaxy S6, Android, Paris, France) confirmed the previously observed dependencies. The smallest - that is the most advantageous - value of the Mobile Speed Index was recorded in the case of the application, which was made based on WebP files, and the worst result was 
obtained in the case of an application presenting images in PNG format. This is related to the size of application component files (Table 5).

Table 5. Measurement results for selected performance indices (mobile mode)

\begin{tabular}{|l|c|c|c|}
\hline \multicolumn{1}{|c|}{ Analysis tool } & Size of component files & $\begin{array}{c}\text { Dareboost } \\
\text { Performance grade [\%] }\end{array}$ & $\begin{array}{c}\text { Dareboost Mobile } \\
\text { Speed Index }\end{array}$ \\
\hline Version I (JPG) & 7216 & 54 & 2702 \\
\hline Version II (PNG) & 10956 & 56 & 4860 \\
\hline Version III (WebP) & 4848 & 60 & 2490 \\
\hline
\end{tabular}

Source: Author's own study

In the case of mobile devices, the performance of the mapping application does not predetermine its usability. True enough, the time of application rendering is important, but even a quickly loaded application can be difficult or awkward to use. Equally important as efficiency are design issues, such as: the use of fonts of appropriate size, so that they do not hamper the reading of the text, and the placement of active elements (such as navigation buttons) at an optimal distance from each other. The synergy of inefficiencies and design errors can lead to the application being unserviceable, which can be reported, for example, by a high bounce rate.

\section{Conclusions}

Performance indicators have an illustrative, synthetic value. The results of their measurement should not be treated as absolute. This is due to the complexity of relationships taking place in the Internet ecosystem between the website (consisting of components), the data server, and the quality of the Internet connection. However, performance testing can be helpful in choosing a raster file for a specific application. In practice, knowledge of the subject and in-depth qualitative analysis may also be useful, regarding not only the performance of individual components, but also the performance of the entire website. It turns out that although WebP files are characterized by good quality with a small file size, this format is not very popular and is not widely used. Even the use of WebP files in the most popular social networking sites and Google support did not change this. In practice, it may turn out that the use of WebP can bring some benefits in terms of performance - but that these advantages will not actually be perceptible to the users. In addition, in selected web browsers, problems may occur in displaying these files.

The choice of an extension - between JPG, PNG, WebP or another - may depend on the expected performance of the application, but also on the expected "visual quality" of the image itself. The visual quality was the lowest in the case of JPG raster, which was manifested in the form of small artefacts created as a result of data compression, 
that is, image defects in the form of blurring or clouding of outlines, lack of sharpness. These imperfections were more pronounced in images with smaller resolutions, where there was a greater density of the edges of the objects. At the same time, however, these imperfections could remain imperceptible to the average user. It can therefore be assumed that in applications based on raster maps, which are only illustrative, temporary, and ad-hoc, preserving high quality of images at the expense of application performance is not justified.

\section{References}

Akamai 2017. Online Retail Performance Report: Milliseconds Are Critical. https://goo. gl/72fpyT (accessed: 03.04.2019).

Boniecki P., Nowakowski K., Przybylak A. 2009. Neuronowa kompresja danych graficznych w procesie identyfikacji wybranych obiektów rolniczych. Journal of Research and Applications in Agricultural Engineering, 54(2), 19-23.

Borawski M. 2011. Kompresja JPG obrazu sonarowego z uwzględnieniem założonego poziomu błędu. Biuletyn Wojskowej Akademii Technicznej, 60(3), 227-245.

Brailovskiy I., Plotkin D. 2008. Modified JPEG algorithm with Binary Interval Transform coding with improved compression ratio. Proceedings GraphiCon, Moscow State University.

Congalton R.G. 1997. Exploring and evaluating the consequences of vector-to-raster and rasterto-vector conversion. Photogrammetric Engineering and Remote Sensing, 63(4), 425-434.

Farkas G. 2017. Applicability of open-source web mapping libraries for building massive Web GIS clients. Journal of Geographical Systems, 19(3), 273-295.

Ginesu G., Pintus M., Giusto D.D. 2012. Objective assessment of the WebP image coding algorithm. Signal Processing: Image Communication, 27(8), 867-874.

Kocur-Bera K. 2011. Use of the GIS platform in crisis management. Acta Sci. Pol., ser. Administratio Locorum, 10(4), 27-39.

Kocur-Bera K., Dudzińska M. 2014. Industrial databases for spatial management support. Environmental Engineering. Proceedings of the International Conference on Environmental Engineering. ICEE, 9, 1-6. DOI: 10.3846/enviro.2014.217

Król K. 2016. Data presentation on the map in Google Charts and jQuery JavaScript technologies. Geomatics, Landmanagement and Landscape (GLL), 2, 91-106. DOI: 10.15576/ GLL/2016.2.91

Król K. 2018a. Comparative analysis of the performance of selected raster map viewers. Geomatics, Landmanagement and Landscape (GLL), 2, 23-32. DOI: 10.15576/GLL/2018.2.23

Król K. 2018b. Performance threshold of the interactive raster map presentation - as illustrated with the example of the jQuery Java Script component. Geographic Information Systems Conference and Exhibition GIS ODYSSEY 2018, 321-327.

Król K., Prus B. 2017. Dynamic presentation of static maps using GIS and jQuery JavaScript tools taking data of soil maps in Poland as an example. Geographic Information Systems Conference and Exhibition GIS ODYSSEY 2017, 203-212.

Król K., Szomorova L. 2015. The possibilities of using chosen jQuery JavaScript components in creating interactive maps. Geomatics, Landmanagement and Landscape (GLL), 2, 45-54.

Malicka M., Żyła K. 2011. Google Web Toolkit jako przykład narzędzia do tworzenia wielofunkcyjnych aplikacji GIS wykorzystujących technologie webowe. Logistyka, 3, 1745-1754.

Mohler A. 2019. Mapbox: Zoomable jQuery Map Plugin, http://wayfarerweb.com/jquery/ plugins/mapbox (accessed: 03.04.2019). 
Nielsen J. 1997. The Need for Speed. Nielsen Norman Group, https://www.nngroup.com/articles/the-need-for-speed/ (accessed: 29.03.2019).

Prus B., Król K., Chrobot K. 2018. Analysis of the correlation between socio-economic development and land prices - A study of the Zagnańsk municipality, Acta Sci. Pol., ser. Formatio Circumiectus, 17(2), 87-94. DOI: 10.15576/ASP.FC/2018.17.2.87

Si Z., Shen K. 2016. Research on the WebP Image Format. [In:] Ouyang Y., Xu M., Yang L., Ouyang Y. (eds). Advanced Graphic Communications, Packaging Technology and Materials. Lecture Notes in Electrical Engineering, 369. Springer, Singapore.

Starosolski R. 2004. Przegląd metod bezstratnej kompresji obrazów medycznych. Studia Informatica, 2(58), 49-66.

Dr inż. Karol Król

Uniwersytet Rolniczy w Krakowie

Katedra Gospodarki Przestrzennej Architektury Krajobrazu

30-198 Kraków, ul. Balicka 253c

e-mail:k.krol@ur.krakow.pl

website: http://homeproject.pl

ORCID:https://orcid.org/0000-0003-0534-8471

Dr hab. Agnieszka Bitner

Uniwersytet Rolniczy w Krakowie

Katedra Geodezji Rolnej, Katastru i Fotogrametrii

30-198 Kraków, ul. Balicka 253a

e-mail: agnieszka.bitner@urk.edu.pl

ORCID: 0000-0002-5733-3987 